\title{
The HIV transactivator TAT binds to the CDK-activating kinase and activates the phosphorylation of the carboxy-terminal domain of RNA polymerase II
}

\author{
Thomas P. Cujec, ${ }^{1}$ Hiroshi Okamoto, ${ }^{1}$ Koh Fujinaga, $^{1}$ Jon Meyer, ${ }^{1}$ Holly Chamberlin, ${ }^{2}$ \\ David O. Morgan, ${ }^{2}$ and B. Matija Peterlin ${ }^{1,3}$ \\ ${ }^{1}$ Howard Hughes Medical Institute, Departments of Medicine, Microbiology, and Immunology; ${ }^{2}$ Department of Physiology, \\ University of California at San Francisco, San Franscisco, California USA
}

The human immunodeficiency virus encodes the transcriptional transactivator Tat, which binds to the transactivation response (TAR) RNA stem-loop in the viral long terminal repeat (LTR) and increases rates of elongation rather than initiation of transcription by RNA polymerase II (Pol II). In this study, we demonstrate that Tat binds directly to the cyclin-dependent kinase 7 (CDK7), which leads to productive interactions between Tat and the CDK-activating kinase (CAK) complex and between Tat and TFIIH. Tat activates the phosphorylation of the carboxy-terminal domain (CTD) of Pol II by CAK in vitro. The ability of CAK to phosphorylate the CTD can be inhibited specifically by a CDK7 pseudosubstrate peptide that also inhibits transcriptional activation by Tat in vitro and in vivo. We conclude that the phosphorylation of the CTD by CAK is essential for Tat transactivation. Our data identify a cellular protein that interacts with the activation domain of Tat, demonstrate that this interaction is critical for the function of Tat, and provide a mechanism by which Tat increases the processivity of Pol II.

[Key Words: HIV; transactivator Tat; phosphorylation; CTD; Pol II; CAK; CDK7]

Received July 8, 1997; revised version accepted August 19, 1997.

The human immunodeficiency virus (HIV) encodes a highly conserved transcriptional transactivator Tat, that is expressed early in the viral life cycle and is essential for viral replication and progression to disease (Cullen 1993; Jones and Peterl in 1994). Tat binds to the transactivation response (TAR) RNA stem-loop located from positions +1 to +60 in the viral $5^{\prime}$ long terminal repeat (LTR). Interactions between Tat and TAR are absolutely required for the increased processivity of RN A polymerase II (Pol II) and the production of full-length viral transcripts (Kao et al . 1987; Laspia et al. 1989; Marciniak and Sharp 1991; Kato et al. 1992). Tat is unique because it is the only eukaryotic transcription elongation factor known to function via RN A (Madore and Cullen 1995). Although the mechanism by which Tat increases transcription el ongation rates is unknown, common regulatory themes must exist between viral and cellular genes because Tat can relieve Pol II pausing when artificially targeted to the c-myc promoter (Wright et al. 1994).

Tat can be divided into two functional domains. The activation domain contains 48 amino-terminal amino acids and interacts with the cellular transcriptional ma-

${ }^{3}$ Corresponding author.

E-MAIL MATIJA@TSA.UCSF.EDU; FAX (415) 502-5081. chinery. A 10-amino-acid basic domain is required for the binding of Tat to TAR (Jones and Peterlin 1994). CelIular proteins are clearly required for the function of Tat (Carroll et al. 1992; Madore and Cullen 1993). At least one protein, encoded by the human chromosome 12, is required for the efficient binding of Tat to TAR (Hart et al. 1989; Alonso et al. 1992). Numerous other proteins have been postulated to interact with the activation domain of Tat. These include general transcription factors (GTFs) such as the core Pol II (Mavankal et al. 1996), the TATA box-binding protein (TBP) (Kashanchi et al. 1994; Veschambre et al. 1995), the TBP-associated factor TAF $_{11} 55$ (Chiang and Roeder 1995) and TFIIH (Blau et al. 1996; Parada and Roeder 1996). Upstream DN A-bound activators such as Spl have also been identified as possible co-activators of T at (Jeang et al. 1993). In addition, a wide variety of other proteins that interact with Tat but whose role in transcription is somewhat unclear have al so been identified ( $\mathrm{N}$ elbock et al. 1990; Desai et al. 1991; Zhou and Sharp 1996). Recently, T at has been demonstrated to interact with the Pol II holoenzyme (Cujec et al. 1997). This large megadal ton complex consists of core Pol II, a subset of general transcription factors (TFIIE, TFIIF, TFIIH), human SRBs (suppressors of mutations in $\underline{R} N$ A polymerase $\underline{B}$ ), which confer the abil- 
ity of the Pol II holoenzyme to respond to activators and proteins involved in chromatin remodeling (SWI/SNF) and DN A repair (Kim et al. 1994; Ossipow et al. 1995; Chao et al. 1996; Maldonado et al. 1996; Wilson et al. 1996).

TFIIH contains nine polypeptides [ERCC3, ERCC2, p62, p54, p44, CDK7 (M O 15), cyclin H, MAT 1, and p34] (Drapkin and Reinberg 1994; Hoeijmakers et al. 1996). It contains a kinase activity that can phosphorylate the carboxy-terminal domain (CTD) of Pol II (Feaver et al. 1991; Lu et al. 1992). The kinase activity resides in the cyclin-dependent kinase 7 (CDK7) subunit (Feaver et al . 1994; Roy et al. 1994; Serizawa et al. 1995; Shiekhattar et al. 1995). In association with cyclin $H, C D K 7$ forms the CDK-activating kinase (CAK) complex that phosphorylates CDKs involved in the regulation of the cell cycle. Association of MAT 1 with the CAK dimer stabilizes the complex and allows for the activation of CAK independently of the phosphorylation of CDK7 on the threonine at position 170 (Fisher and Morgan 1994; Fisher et al. 1995). M oreover, the CAK trimer is much more efficient at phosphorylating the CTD than the CAK dimer (Rossignol et al. 1997; Yankulov and Bentley 1997). The tripartite CAK can exist in three distinct complexes in cells. The majority is present as free CAK. However, CAK can also exist as a CAK-ERCC2 complex as well as in association with the core TFIIH (ERCC 3, p62, p54, p44, and p34) (Drapkin et al. 1996; Reardon et al. 1996). The association of CAK with TFIIH confers kinase activity to TFIIH and renders it transcriptionally competent. Interestingly, the yeast homolog of CDK7, Kin28, is found only in a complex with TFIIH and is devoid of CAK activity (Cismowski et al. 1995). Instead, CAK activity resides in a novel protein called Civ1 or CAK1p (Kladis et al. 1996; Thuret et al. 1996).

The eukaryotic Pol II is unique among polymerases in that it contains multiple heptapeptide repeats of the sequence YSPTSPS, which together comprise the CTD (Dahmus 1994, 1995). A large number of kinases capable of phosphorylating the CTD in vitro have been identified. However, the functional rel evance of these kinases remains unclear. To date, CDK7/cyclin $\mathrm{H}$ (TFIIH) and CDK8/cyclin C (human homologs of the yeast SRB10/ SRB11) are the major kinases associated with transcription factors that can phosphorylate the CTD (Liao et al. 1995; Serizawa et al. 1995; Shiekhattar et al. 1995).

Pol II enters into the assembling transcription complex with its CTD unphosphorylated (IIA form). However, the CTD of elongating polymerases is highly phosphorylated (Ilo form) primarily on its serine and threonine residues (Laybourn and Dahmus 1989, 1990). This observation led to the suggestion that the phosphorylation of the CTD is important for promoter clearance and for the processivity of Pol II. Numerous additional observations support this contention: (1) the CTD of polymerases paused on the Drosophila hsp 70 promoter before heat shock activation are hypophosphorylated (Ila), whereas those of activel y el ongating polymerases are hyperphosphorylated (Ilo) (O'Brien et al. 1994); (2) inhibitors of CTD kinases inhibit promoter clearance and elon- gation of Pol II in vitro (Yankulov et al. 1995, 1996); (3) the kinase activity of TFIIH is required for the clearance of the DHFR promoter but not for the initiation of its transcri ption (Akoulitchev et al. 1995); and (4) mutations in the yeast Pol II CTD, the yeast homolog of CDK7 (Kin 28), or SRB2, a subunit of the Pol II holoenzyme, each inhibit the processivity of Pol II in vivo (Akhtar et al. 1996). The identification of CTD-binding proteins with homology to serine/arginine-rich (SR) proteins suggest that the phosphorylation of the CTD might also provide a mechanism for coupling transcription and pre-mRN A processing (Yuryev et al. 1996).

Recently, we and others demonstrated that the CTD is absolutely required for the production of long transcripts from the HIV LTR in vitro and in vivo (Chun and Jeang 1996; Okamoto et al. 1996; Parada and Roeder 1996; Y ang et al. 1996). In contrast, basal transcription and the production of short transcripts from the HIV LTR is independent of the CTD. Together these results suggested an important role for the CTD in the function of Tat.

Given the critical role of the CTD for the function of Tat, and the fact that TFIIH is part of the Pol II holoenzyme that interacts with $\mathrm{T}$ at, we examined the possibility that Tat might interact with TFIIH. In this study, we report that Tat co-immunopreci pitates with TFIIH/CAK complexes in vivo. Furthermore, Tat binds to recombinant CAK in vitro and this association is mediated by direct interactions between Tat and CDK7. Functional relevance for this association is provided by experiments that demonstrate that $T$ at potentiates the ability of TFIIH and CAK to phosphorylate the CTD of Pol II. Finally, using specific pseudosubstrate peptides, which inhibit the activity of the CDK7 kinase, we demonstrate that the phosphorylation of the CTD by CDK7 is re quired for Tat transactivation in vitro and in vivo.

\section{Results}

Tat interacts with TFIIH in vivo

We demonstrated recently that Tat interacts with the Pol II holoenzyme (Cujec et al. 1997). Given that TFIIH is present in the Pol II holoenzyme (Ossipow et al. 1995; Maldonado et al. 1996) and the essential role that the phosphorylation of the CTD by TFIIH is believed to have in the processivity of Pol II, we examined whether Tat can associate with TFIIH independently of the Pol II holoenzyme. To determine whether Tat interacts with TFIIH in vivo, hemagglutinin (HA)-tagged wild-type and mutant Tat proteins were expressed in COS cells. Immunoprecipitations were done with an antibody that is specific for ERCC3 $(\alpha E R C C 3)$, the largest subunit of TFIIH (Drapkin et al. 1996). Because TFIIH is part of the Pol II holoenzyme, coimmunoprecipitations were done under stringent conditions $(0.5 \mathrm{M} \mathrm{N} \mathrm{aCl}$ and $1 \%$ Triton $X-100)$, which were expected to dissociate TFIIH from the Pol II holoenzyme. To confirm that only TFIIH, and not the entire Pol II holoenzyme, was immunoprecipitated in these experiments, $\alpha$ ERCC 3 immunoprecipitates were also probed with antibodi es against the largest 
A

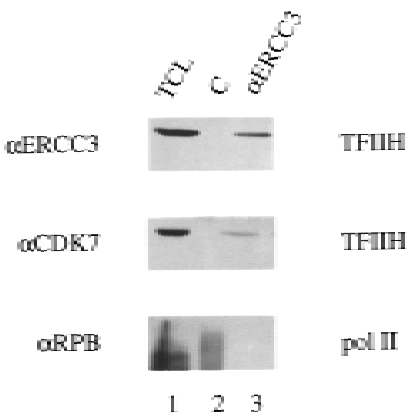

B

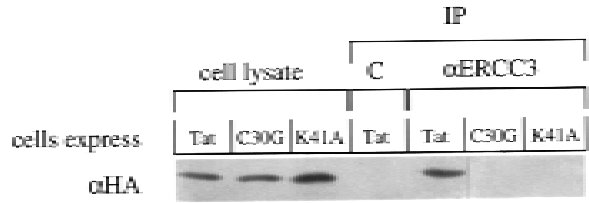

Western blot

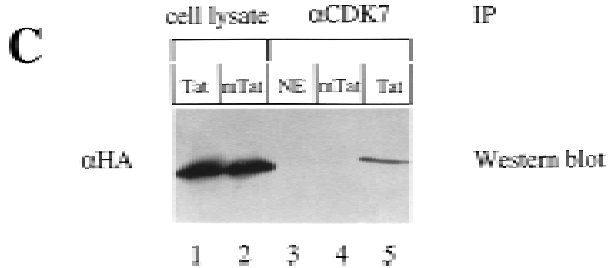

Figure 1. Tat associates with TFIIH in the absence of the Pol II hol oenzyme in vivo. (A) Total cell lysates (TCL) from COS cells were immunoprecipitated with $\alpha$ CIITA (lane 2) or $\alpha$ ERCC 3 antibodies (lane 3). One-third of the lysate was used as the input control (lane 1). Samples were separated by SDS-PAGE, transferred to membranes, and probed with the antibodies indicated on the left. (B) COS cells expressed HA-tagged wild-type (T at) or mutant (C 30G or K41A) Tat proteins. Cell lysates were immunoprecipitated with either the $\alpha$ CIITA (C) antibody or the $\alpha$ ERCC 3 antibody ( $\alpha$ ERCC 3 ). Equal amounts of the lysates were loaded as input controls. Samples were processed as in A and probed with the $\alpha \mathrm{HA}$ antibody. (C) Nuclear extracts (NE) or lysates from cells expressing HA-tagged wild-type Tat (Tat) or mutant $\mathrm{T}$ at $(\mathrm{mT}$ at $=\mathrm{K} 41 \mathrm{~A})$ were immunopreci pitated with the $\alpha$ CDK7 antibody. One-half of these cell lysates were loaded as input controls (lanes 1,2). Samples were processed and blots probed with $\alpha \mathrm{HA}$ antibodies as described above.

subunit of the core Pol II (RPB1) (Thompson et al. 1989). As shown in Figure $1 \mathrm{~A}, \alpha$ ERCC 3 antibodies efficiently precipitated ERCC 3 and CDK7 subunits of TFIIH, but failed to preci pitate Pol II (Fig. 1A, lane 3). As a control, antibodies against the transcriptional activator CIITA (C) (Steimle et al. 1993) failed to coimmunoprecipitate any of the transcription factors (Fig. 1A, Iane 2). To determine if Tat could bind to TFIIH in vivo, $\alpha$ ERCC 3 immunoprecipitates were probed with $\alpha \mathrm{HA}$ antibodies. As shown in Figure 1B, al though equivalent amounts of wild-type (Tat) and mutant (C30G and K41A) Tat proteins were expressed in COS cells (Fig. 1B, left three lanes), only the wild-type Tat was coimmunoprecipitated by the $\alpha$ ERCC 3 antibodies (Fig. 1B, right three lanes). Again, antibodies against the transcriptional ac- tivator CIITA (C) failed to coi mmunoprecipitateT at (Fig 1B). Similar results were obtained when using $\alpha$ CDK7 antibodies (Fig. 1C). Together, these results demonstrate that Tat can interact with TFIIH in the absence of both the Pol II holoenzyme and TAR in vivo.

Tat Binds to CDK7 in vitro

Although we could detect readily an interaction between Tat and purified TFIIH in vitro (Parada and Roeder 1996; data not shown), repeated attempts to detect specific interactions between Tat and ERCC 3 , ERCC 2 , or p62 subunits of TFIIH were unsuccessful. Of these proteins, only p62 bound to Tat and all our mutant Tat proteins (data not shown). Therefore, we tested whether Tat could bind to recombinant CAK in vitro (Fig. 2). Recombinant wildtype and mutant Tat proteins were attached to streptavidin agarose beads by virtue of streptavidin-binding peptides at their 3' termini (Cujec et al. 1997). CDK7, cyclin $\mathrm{H}$, and MAT 1 were coexpressed in insect cells by baculovirus infection. Extracts were purified initially over a HiTrap chelating column and then an anion exchange column (HiTrap Q). Relevant fractions were purified further by gel filtration and concentrated on a second $\mathrm{Hi}$ Trap Q column (see M aterial s and M ethods). The resulting CAK preparations were $>99 \%$ pure and were subsequently used for crystal lization studies (data not shown). CAK was incubated with streptavidin-agarose beads al one $(C)$ or with streptavidin-agarose beads containing wild-type (Tat) or mutant $(\mathrm{mT}$ at $=\mathrm{K} 41 \mathrm{~A}) \mathrm{T}$ at proteins bound to them. After washing, the presence of CAK was monitored by Western blotting using $\alpha \mathrm{cycl}$ in $\mathrm{H}$ antibodies. As shown in Figure 2, wild-type Tat (Fig. 2, lane 4), but not mutant Tat (Fig. 2, lane 5), bound to CAK very efficiently, as at least half of the input CAK was retained on Tat beads (Fig. 2, cf. lanes 2 and 4 with 5). Western blotting with $\alpha$ CDK 7 and $\alpha$ MAT 1 antibodies revealed the presence of the other CAK subunits as well (data not shown). Tat proteins containing other debilitating mutations in their activation domains (C22G or C30G) (Kuppuswamy et al. 1989; Madore and Cullen 1993; Cujec et al. 1997) al so failed to bind recombinant CAK in vitro (data not shown).

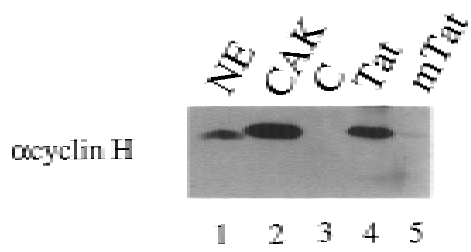

Figure 2. Tat associates with recombinant CAK in vitro. Recombinant CAK trimer $(50 \mathrm{ng})$ was incubated with the wildtype (Tat) or mutant ( $\mathrm{mT}$ at $=\mathrm{K} 41 \mathrm{~A}$ ) T at proteins $(1 \mu \mathrm{g})$ bound to streptavidin-agarose beads or with streptavidin-agarose beads al one as the control (C). N ucl ear extract $(10 \mu \mathrm{g}$, lane 1$)$ or CAK (50 ng, lane 2) were loaded as input controls. After washing, the streptavidin beads and controls were subjected to SDS-PAGE, transferred to membranes, and probed with the $\alpha$ cyclin $\mathrm{H}$ antibody. 
We next tested the ability of each of the individual CAK subunits to bind to Tat. CDK7, cyclin $\mathrm{H}$, and MAT 1 were label ed with [ $\left.{ }^{35} \mathrm{~S}\right] \mathrm{methionine}$ by in vitro translation and CAK dimers or trimers were allowed to form. Complexes were immunoprecipitated with $\alpha$ CDK7 antibodies bound to protein-A-Sepharose beads. Immunoprecipitated complexes were then incubated with [ $\gamma$ ${ }^{32}$ P]ATP-labeled Tat and the ability of CDK7 beads to retain Tat was evaluated. As demonstrated in Figure 3, equal amounts of $T$ at were retained on these beads regardless of whether CDK 7 was present al one (Fig. 3, Iane 6), as a dimer with cyclin $\mathrm{H}$ (Fig. 3, lane 9), or as the CAK trimer (Fig. 3, lane 12). Although equivalent amounts of wild-type $(T)$ or mutant ( $\mathrm{mT}$ ) Tat proteins were used in these experiments (Fig. 3, lanes 13,14), the mutant Tat did not bind to any CDK7 complexes. As expected, addition of MAT 1 to the CDK7-cyclin $\mathrm{H}$ dimers stabilized the CAK complex (Fisher et al. 1995) and increased the amount of CAK immunoprecipitated by $\alpha$ CDK 7 antibodies (Fig. 3, cf. lane 7 with 10). These results suggest that the reticulocyte lysate used for in vitro translation contained minimal amounts of endogenous cyclin $\mathrm{H}$ or MAT 1 proteins that could associate with the introduced CDK7 monomer or CDK7-cyclin $\mathrm{H}$ dimer and form the tripartite CAK complex. Similar experiments failed to reveal specific interactions between Tat and cyclin $\mathrm{H}$ or MAT 1 in the absence of CDK7 (data not shown). Together these results demonstrate that Tat can interact with CDK 7 di rectly and that this interaction leads to the

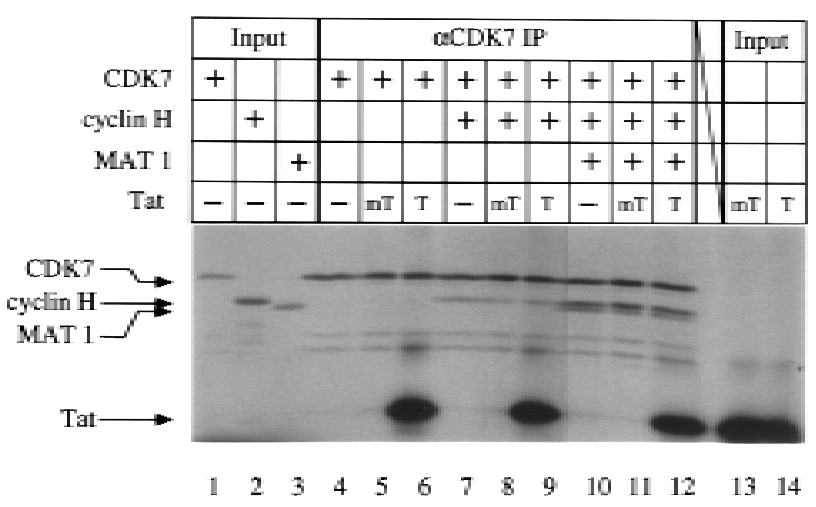

Figure 3. Tat associates with recombinant CDK7 in vitro. CDK7, cyclin $\mathrm{H}$, and MAT 1 (p36) were labeled with ${ }^{35} \mathrm{~S}$ by translation in vitro. CDK7 alone (lanes 4-6), in combination with cyclin $\mathrm{H}$ (lanes 7-9), or as a mixture with cyclin $\mathrm{H}$ and MAT 1 (lanes 10-12), was immunoprecipitated with $\alpha$ CDK7 antibodies bound to protein-A-Sepharose beads. Immunoprecipitates were divided into three fractions. Whereas one-third served as a control for immunoprecipitations (lanes 4,7,10), the remaining two-thirds were incubated with wild-type $(T)$ or mutant $(\mathrm{mT}=\mathrm{K} 41 \mathrm{~A})$ Tat proteins labeled at their $3^{\prime}$ termini with $\left[\gamma_{-}{ }^{32} \mathrm{P}\right] A T P$ using the catalytic subunit of CAMP-dependent heart muscle kinase. After washing, the beads were subjected to SDS-PAGE. Gels were dried and visualized by autoradiography. One-fifth of the wild-type and mutant Tat proteins used in the binding reactions were loaded as the input controls (lanes 13,14). association of Tat with the higher order CAK and TFIIH complexes.

Tat increases the ability of CAK to phosphorylate the CTD

Having demonstrated a strong affinity between Tat and CAK, we wished to determine whether Tat affected the ability of CAK to phosphorylate the CTD of Pol II. Wildtype or mutant CAK/TFIIH complexes were immunoprecipitated from lysates of cells that stably expressed HA-tagged wild-type CDK7 or its kinase-deficient variant (D 155A). Although this mutation (D 155A) abolishes the kinase activity of CDK7, it does not affect its ability to bind to cyclin $\mathrm{H}$ and MAT 1 (D.O. Morgan, unpubl.). Immunoprecipitates were incubated for increasing lengths of time with recombinant CTD and wild-type or mutant Tat proteins (Fig. 4A). The phosphorylation of the CTD by casein kinase (CK) was used as a marker for the el ectrophoretic mobility of the CTD (Fig. 4A, lane 1). Because casein kinase only phosphorylates the CTD at one site (Dahmus 1996), only the hypophosphorylated form of the CTD is apparent (Fig. 4, Iane 1). Importantly, this control demonstrates that only the hypophosphorylated form of the CTD (CTD $\mathrm{a}_{\mathrm{a}}$ ) is present in our protein preparations. Wild-type but not mutant (mTat) Tat proteins increased the ability of immunoprecipitated CAK/ TFIIH complexes to phosphorylate the hypophosphorylated $\left(C T D_{a}\right)$ and hyperphosphorylated $\left(C T D_{o}\right)$ forms of the CTD. The effect of Tat was evident after 20 min and increased throughout the duration of the experiment (Fig. 4A, cf. Ianes 2-5 with 6-9). Interestingly, T at did not affect the ability of CAK/TFIIH complexes to autophosphorylate cyclin $\mathrm{H}$. As a control for the specificity of our immunoprecipitations, kinase-deficient CAK/TFIIH complexes (M) were also immunoprecipitated. As expected, these complexes failed to phosphorylate the CTD and cyclin H (Fig. 4A, lane 10).

Because approximately $10 \%$ of CAK is part of $\mathrm{TFIIH}$, and the rest exists as a free complex (Drapkin and Reinberg 1994; Fisher and Morgan 1994; Fisher et al. 1995), immunopreci pitations with $\alpha$ CDK 7 anti bodies would be expected to yield both CAK and some TFIIH. To test directly whether Tat could affect the ability of CAK to phosphorylate the CTD, recombinant CAK was incubated with the CTD in the presence or absence of wildtype or mutant $T$ at proteins. As demonstrated in Figure $4 \mathrm{~B}$, wild-type $\mathrm{Tat}$ (Tat) was much more effective at stimulating the ability of CAK to phosphorylate the CTD than the mutant Tat protein (mTat) (Fig. 4B, cf. lanes 3 and 4 with 2, 5, and 6). The wild-type Tat al so increased the ability of CAK to phosphorylate highly purified preparations of Pol II (Fig. 4C). In neither case did Tat affect the phosphorylation of cyclin $\mathrm{H}$. The CDK7 monomer was incapable of phosphorylating the CTD (data not shown). By demonstrating that $T$ at can increase the kinase activity of CDK7, we provide functional relevance for the binding results presented in the previous section.

To test for the specificity of these effects of Tat, we 
A

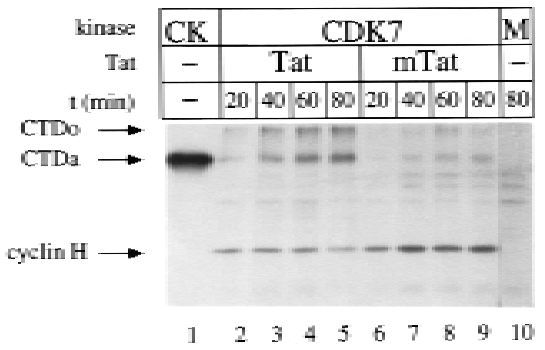

B

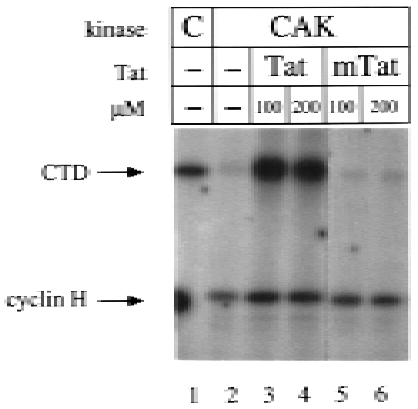

C
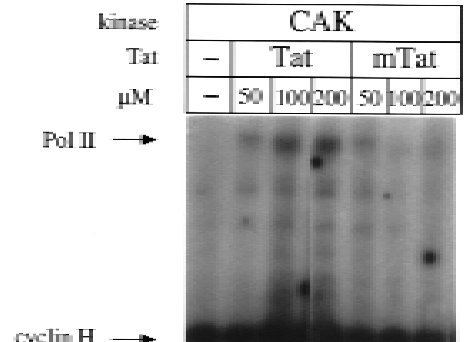

$\mathrm{lin} \mathrm{H} \longrightarrow$

D

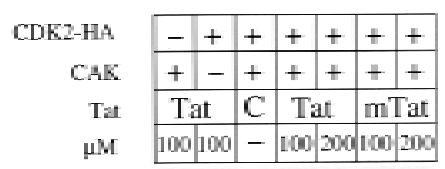

$\mathrm{HI} \rightarrow$
Figure 4. Tat increases the ability of CAK to phosphorylate the CTD of Pol II. (A) Wild-type HA-tagged CDK7 (CDK7), or a kinase-deficient mutant of CDK7 (M) were immunoprecipitated from stably expressing HeLa cells. GST-CTD protein ( $25 \mathrm{ng}$ ) was incubated with casein kinase (CK, 25 ng), or CDK7 immunoprecipitates in the presence of wild-type (Tat) or mutant $(\mathrm{mT}$ at $=\mathrm{K} 41 \mathrm{~A})$ Tat proteins and $\gamma$-ATP. Kinase reaction products were subjected to SDS-PAGE, and gels were visual ized by autoradiography after drying. Positions of the hypophosphorylated (CTD $)$ and hyperphosphorylated (CTD。) GST-CTD fusions, as well as cyclin $\mathrm{H}$ are indicated on the left. (B) GST-CTD was incubated with recombinant CAK (50 ng) in the presence of wild-type (Tat) or mutant $(\mathrm{mT}$ at $=\mathrm{K} 41 \mathrm{~A}) \mathrm{T}$ at proteins in a kinase reaction. Products were processed as described above. (C) Purified Pol II was incubated with CAK in the presence of wild-
essed as described above. (D) CyclinA $\Delta 171$ / type (Tat) or mutant ( $\mathrm{mT}$ at $=\mathrm{K} 41 \mathrm{~A})$ Tat proteins in a kinase reaction. Products were processed as described above. (D) CyclinA $\Delta 171 /$
CDK2HA complexes bound to protein-A-Sepharose beads were incubated with CAK $(50 \mathrm{ng})$ in the presence of wild-type (Tat) or mutant ( $\mathrm{mT}$ at $=\mathrm{K} 41 \mathrm{~A}$ ) T at proteins. After washing the beads were incubated with histone $\mathrm{H} 1$ and kinase reactions allowed to proceed for $1 \mathrm{hr}$. Products were processed as described above. Position of labeled histone $\mathrm{Hl}(\mathrm{H} 1)$ is indicated. next examined whether Tat affected the ability of CAK to phosphorylate cyclinA $\Delta 171 / C D K 2 H A$ complexes. CyclinA $\triangle 171 / C D K 2 H A$ complexes were bound to protein-A-Sepharose beads and incubated with CAK in the presence of wild-type or mutant Tat proteins. Because the ability of cyclinA $\triangle 171 / C D K 2 H A$ to phosphorylate histone $\mathrm{HI}$ is dependent on the phosphorylation of CDK2 by CAK, the phosphorylation of histone $\mathrm{H} 1$ can be used as a measure of CAK activity (Fisher and Morgan 1994). As shown in Figure $4 D$, neither the wild-type (Tat) nor mutant Tat (mTat) affected the ability of CAK to phosphorylate cyclinA $\Delta 171 / C D K 2 H A$. As expected, $\mathrm{H} 1$ was not phosphorylated if either cyclinA $\Delta 171$ / CDK2HA or CAK were omitted from the reaction. Furthermore, these controls demonstrate that our Tat preparation did not contain a kinase activity capable of activating cyclinA $\Delta 171 / C D K 2 H A$.

A CDK2 mutant peptide inhibits the phosphorylation of the CTD by CAK

The activity of some kinases can be inhibited by excess amounts of substrate peptides that contain a mutation in the amino acid phosphorylated by the kinase of interest (Poteet-Smith et al. 1997). Because CAK phosphorylates the threonine of CDK2 at position 160 (Fisher and M organ 1994; M akel a et al . 1994), we tested whether a CDK2 peptide (amino acids 149-170) having a T $\rightarrow$ A mutation (mC2p) could inhibit phosphorylation of the CTD by CAK. Increasing amounts of the CDK2 mutant peptide ( $m C 2 p)$ were added to kinase reactions containing recombinant CAK $(0.02 \mu \mathrm{m})$ in the presence or absence of Tat. As demonstrated in Figure 5A, a 65-fold molar ex-
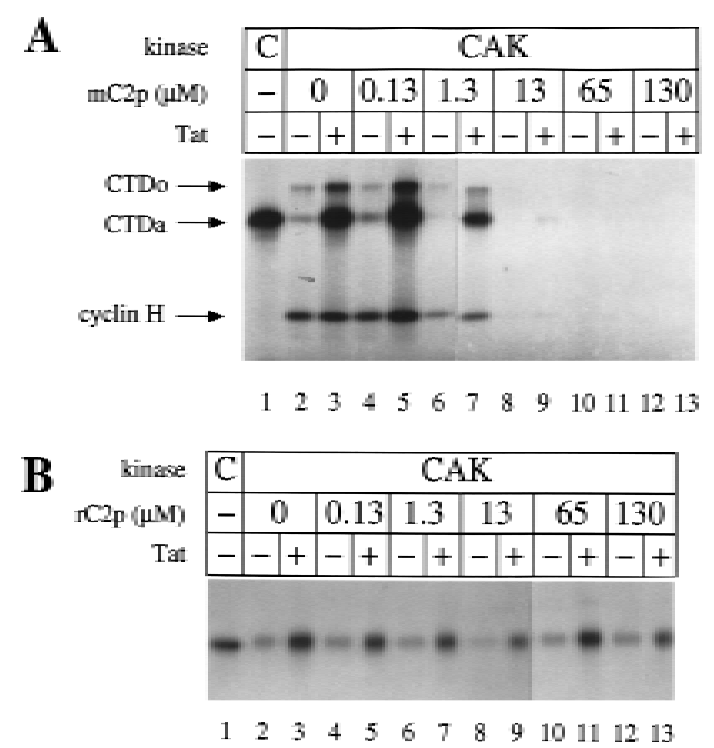

Figure 5. A CDK2 mutant peptide inhibits the phosphorylation of the CTD by recombinant CAK. (A) Increasing concentrations of a mutant CDK2 peptide ( $\mathrm{mC} 2 \mathrm{p}$ ) were added to kinase reactions containing GST-CTD, and CAK in the presence $(+)$ or absence $(-)$ of Tat. Casein kinase was used as a control for the mobility of the labeled GST-CTD (lane 1). Kinase reactions were processed as described in Fig. 4. Positions of the hypophosphorylated $\left(C T D_{a}\right)$ and hyperphosphorylated (CTD $)$ GST -CTD fusions, as well as cyclin $\mathrm{H}$ are indicated on the left. (B) The randomized CDK2 peptide ( $r C 2 p)$ was added to kinase reactions as described in A. The labeled GST-CTD fusion protein is presented. 
cess of $\mathrm{mC} 2 \mathrm{p}(1.3 \mu \mathrm{m})$ inhibited the kinase activity of CAK by $50 \%$, whereas a 650 -fold excess of the peptide $(13 \mu \mathrm{M})$ abolished almost all the activity of CAK. Interestingly, mCp inhibited both Tat-dependent and Tat-independent activity of CAK, as well as the phosphorylation of cyclin $\mathrm{H}$. A randomized peptide ( $\mathrm{rC} 2 \mathrm{p}$ ) having the same net charge and solubility as $\mathrm{mC} 2 \mathrm{p}$ had no effect on the kinase activity of CAK (Fig. 5B). The mutant peptide (mC2p) did not affect the ability of CDK8/cyclin C to phosphorylate the CTD, or the activity of cyclinA $\Delta 171$ / CDK2HA (data not shown).

The mutant peptide inhibits Tat transactivation in vitro

Having demonstrated that Tat binds to CDK7, and that this interaction increases the ability of CAK to phosphorylate the CTD, we next examined more closely the role of CAK in T at transactivation. We took advantage of the fact that mC2p could inhibit the CDK7-mediated kinase activity of CAK to examine the effect of this peptide on the function of Tat in vitro. As shown in Figure $6 \mathrm{~A}$, the addition of recombinant $T$ at to transcription reactions containing the wild-type HIV LTR as the template stimulated transcription 10-fold compared with basal levels (Fig. 6A, lanes 1,2). Increasing concentrations of mC2p selectively inhibited Tat transactivation. At a concentration of $65 \mu \mathrm{m}, \mathrm{mC} 2 \mathrm{p}$ inhibited Tat transactivation to basal levels (Fig. 6A, lanes 9,10), whereas at $130 \mu \mathrm{M}$, transcription was abolished compl etely (Fig. 6A, Iane 12). As a control, the randomized $\mathrm{rC} 2 \mathrm{p}$ peptide did not affect Tat transactivation (Fig. 6B). In contrast, transcription in the absence of Tat was relatively unaffected by $\mathrm{mC} 2 \mathrm{p}$ or $\mathrm{rC} 2 \mathrm{p}$, even at high concentrations of the peptide (130 $\mu \mathrm{m})$ (Fig. 6A and B, cf. Iane 1 with 11). The slight increase in basal transcription at low concentrations of mC2p or rC2p (Fig. 6, cf. Ianes 5, 7, or 9 with 1 in $A$ and $B$ ) suggests that these peptides might also have a nonspecific stabilizing effect on basal transcription. It is surprising that Tat transactivation in vitro is less sensitive to $\mathrm{mC} 2 \mathrm{p}$ concentrations than CAK kinase activity. Perhaps high levels of CAK in nuclear extracts, or the nonspecific binding of the peptide to other proteins in these extracts, can explain the rel atively high concentrations of $\mathrm{mC} 2 \mathrm{p}$ required to affect Tat activity in the in vitro transcription reactions. Furthermore, it is also possible that CAK is less accessible to the peptide when complexed with TFIIH.

To control for the possibility that $\mathrm{mC} 2 \mathrm{p}$ might affect other transcription factors nonspecifically, we tested the effect of the peptide on transcription from adenovirus major late $(\mathrm{AdML})$ and DHFR promoters. These promoters represent important controls because it has been demonstrated that transcription from the $A d M L$ promoter is independent of CDK7, whereas transcription from the DHFR promoter is absolutely dependent on the kinase activity of CDK7 (A koulitchev et al. 1995). As shown in Figure 6C, increasing concentrations of $\mathrm{mC} 2 \mathrm{p}$ had no effect on the transcription from the AdML promoter. In contrast, $\mathrm{mC} 2 \mathrm{p}$ inhibited the transcription from the DHFR promoter by more than $50 \%$ at a concentration of $65 \mu \mathrm{m}$ and completely at a concentration of $130 \mu \mathrm{M}$ (Fig. 6D). The randomized peptide had no effect on transcription from the DHFR promoter (Fig. 6E). These results, together with studies on the inhibition of the kinase activity, suggest that the phosphorylation of
Figure 6. A CDK2 mutant peptide inhibits Tat transactivation. (A) In vitro transcription reactions were done with linearized DNA templates containing the wildtype HIV LTR sequences in the presence $(+)$ or absence $(\rightarrow$ of T at and increasing concentrations of the CDK2 mutant peptide (mC2p). Runoff transcripts (750 nucleotides) were resolved on a $5 \%$ polyacrylamide/urea sequencing gel and exposed to $x$-ray film after drying. (B) Increasing concentrations of the randomized CDK2 peptide ( $\mathrm{rC2} 2 \mathrm{p}$ ) were added to in vitro transcription reactions containing the wild-type HIV LTR sequences in the presence $(+)$ or absence $(\rightarrow$ of Tat. Runoff transcripts were processed as described in A. (C) Increasing concentrations of the mutant CDK2 peptide $(\mathrm{mC} 2 \mathrm{p})$ were added to in vitro transcription reactions containing linearized DNA templates containing the AdML promoter. Lane 7 was identical to lane 1 except that reactions were done in the presence of $\alpha$-amanitin $(\alpha A=2 \mu \mathrm{g} / \mathrm{ml}$ ). Runoff transcripts (390 nucleotides) were processed as described in A. (D) Increasing concentrations of the mutant CDK2 peptide (mC2p) were added to in vitro transcription reactions containing linearized DNA templates containing the DHFR promoter as described in the experimental procedures. Lane 7 was identical to lane 1 except that reactions were done in the presence of $\alpha$-amanitin ( $\alpha \mathrm{A}=2 \mu \mathrm{g} / \mathrm{ml}$ ). Runoff transcripts (390 nucleotides) were processed as described in A. The doublet corresponds to alternate transcription start sites. (E) Increasing concentrations of the randomized CDK2 peptide ( $\mathrm{rC} 2 \mathrm{p}$ ) were added to in vitro transcription reactions as described in $D$.
A

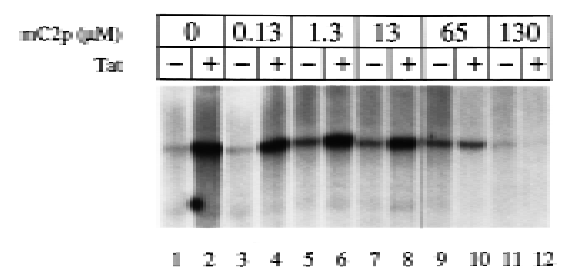

B

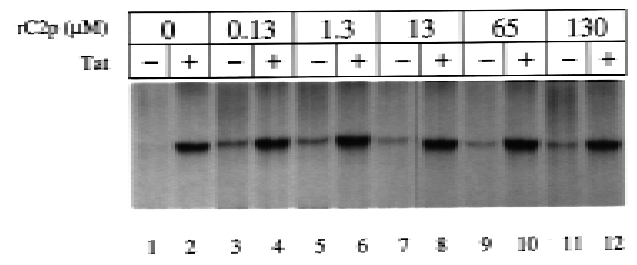

C $\mathrm{C}_{\text {masp (n) }}$

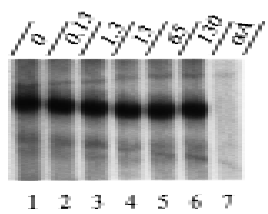

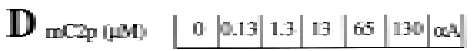

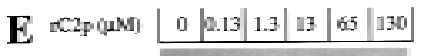
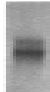

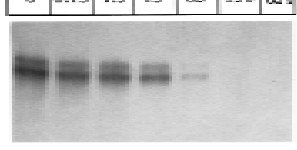


the CTD by CDK7 is required for Tat transactivation in vitro.

\section{CDK7 is required for Tat transactivation in vivo}

To confirm that the kinase activity of CDK7 is required for Tat transactivation in vivo, increasing amounts of the $\mathrm{mC} 2 \mathrm{p}$ peptide were co-electroporated into COS cells, in the presence or absence of Tat (see Materials and $M$ ethods for details). The reporter construct ( $p H I V \triangle K B C A T$ ) consisted of the HIV LTR containing sequences encoding TAR, the initiator, the TATA box, and three Spl-binding sites. Because transcription from the HIV LTR can be activated through N F-кB-binding sites during electroporation, the reporter construct lacked these sites (T ong-Starksen et al . 1987). Levels of specific transcripts were determined by the RN ase protection assay. As documented extensively by our laboratory (Kao et al . 1987; Sel by et al . 1989; Lu et al. 1993) and those of others (Ratnasabapathy et al. 1990; Sheldon et al. 1993), transcription from the HIV LTR in the absence of Tat gives rise to primarily short, nonpolyadenylated transcripts 55-59 nucleotides in length. On the other hand, in the presence of TAT, transcription is highly processive resulting in full-length polyadenylated transcripts that protect an 80-nucleotide-long RNA probe in our RNase protection assays. Consequently, although the levels of short transcripts are a measure of transcription initiation rates, the amount of long transcripts can be used to estimate the efficiency of transcription elongation. Importantly, because $T$ at does not affect transcription initiation rates, short transcripts al so serve as useful internal controls for transfection efficiency and subsequent RNA manipulations. As presented in Figure 7A, the production of long transcripts from the HIV LTR was reduced dramatically in the presence of Iow concentrations of $\mathrm{mC} 2 \mathrm{p}(5 \mu \mathrm{M})$, and abolished completely at a peptide concentration of $10 \mu \mathrm{m}$. In contrast, the production of short transcripts in the presence or absence of Tat was unaffected by $\mathrm{mC} 2 \mathrm{p}$, even at a peptide concentration of $20 \mu \mathrm{m}$. Although overall transcript levels appeared higher in the absence of the randomized peptide (Fig. 7B), the ratio of long to short transcripts remained the same regardless of the pepti de concentration. Similarly, increasing concentrations of $\mathrm{rC} 2 \mathrm{p}$ had no effect on transcription in the absence of Tat (data not shown).

To examine further the role of CDK7 on the activity of Tat in vivo, we overexpressed wild-type or a kinase-deficient mutant (D155A) of CDK7 in COS cells. RN ase protection assays were used to quantify levels of transcripts from the HIV LTR or from an enhancerless promoter consisting of only a TATA box and four Spl-binding sites (4XSpl). This promoter (4XSp1) was shown previously to be independent of the CTD (Gerber et al. 1995) and consequently should not require the kinase activity of CDK7. Transfection of HA-tagged Tat increased dramatically the ratio of long transcripts (LT) to short transcripts (ST) (Fig. 8, top panel). As expected, Tat did not affect transcription from the 4XSpl promoter (Fig. 8, middle panel). The cotransfection of the wild-type
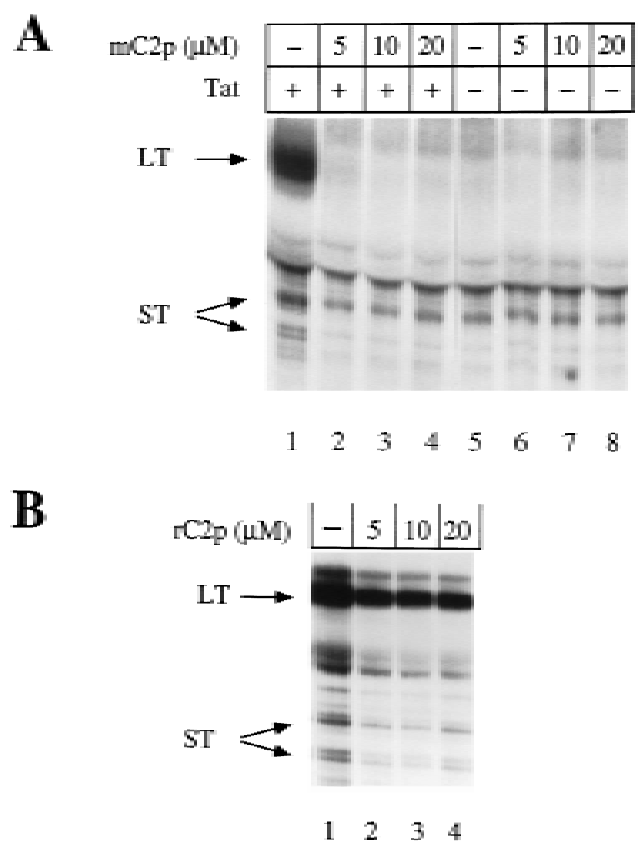

Figure 7. The mutant CDK2 peptide inhibits Tat transactivation in vivo. (A) Increasing concentrations of the mutant CDK2 peptide ( $\mathrm{mC} 2 \mathrm{p}$ ) were cotransfected into COS cells with a reporter plasmid containing HIV LTR promoter sequences that lacked NF-kB-binding sites (pHIV $\triangle$ KBCAT) and either functional $(+)$ or nonfunctional $(-)$ Tat. RN ase protection assays were done with a probe 220 nucleotides long and hybridized to fulllength transcripts of 80 nucleotides (LT) or prematurely terminated transcripts (ST) of 55-59 nucleotides (Okamoto et al. 1996). Protected fragments were resolved on a $11 \%$ polyacrylamide/ urea sequencing gel and exposed to $x$-ray film after drying. (B) Increasing concentrations of the randomized CDK2 peptide $(\mathrm{rC2} 2 \mathrm{p})$ were cotransfected into COS cells with a reporter plasmid containing the HIV LTR lacking NF-kB-binding sites (pHIV $\triangle K B C A T)$ and functional Tat. RN ase protection assays were done as in $A$.

CDK7-HA construct resulted in significant increase in the ratio of long transcripts (LT) to short transcripts (ST) compared with cells expressing only the endogenous CDK7. In contrast, the cotransfection of the kinase-deficient mutant of CDK7 (Mut) inhibited the production of Iong transcripts to levels bel ow those observed in cells expressing endogenous CDK7, but had relatively little effect on the production of short transcripts. As expected, overexpression of wild-type or mutant CDK7 proteins had no effect on transcription from the 4XSpl promoter. As additional controls, Western blotting revealed that similar levels of Tat-HA and CDK-HA proteins were expressed in these experiments (Fig. 8, bottom panels). Together with previous data, these results confirm that the transcriptional activation by Tat in vivo is dependent on the kinase activity of CDK7. In contrast, the synthesis of short transcripts from the HIV promoter is independent of the kinase activity of CDK7.

\section{Discussion}

Our results indicate that Tat binds to CDK7 directly and 


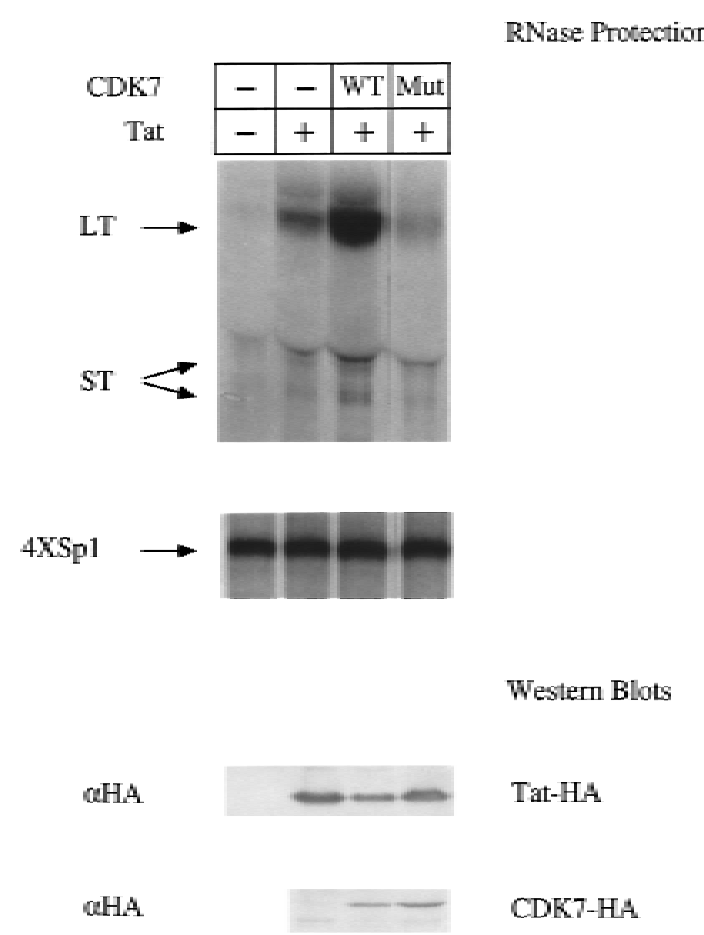

Figure 8. Over-expression of CDK7 affects T at transactivation in vivo. COS cells were cotransfected with HIVSCAT and 4 XSp1 $\beta$ glob reporter plasmids, and plasmids encoding HAtagged functional $(+)$ or nonfunctional $(-)$ Tat, either al one or in combination with wild-type HA-tagged CDK7 (WT) or a kinasedeficient HA-tagged CDK7 (M ut). RN ase protection assays were done using a HIV LTR probe that hybridized to full-length LTRCAT transcripts of 80 nucleotides (LT) or prematurely terminated transcripts (ST) of 55-59 nucl eotides (top panel) and a 216 nucleotide $\beta$-globin probe that hybridized to transcripts of 179 nucleotides (4XSp1) (Okamoto et al. 1996). (Bottom two panels) Lysates from transfected cells were subjected to SDS-PAGE, transferred to membranes and probed with $\alpha \mathrm{HA}$ antibodies to detect Tat-HA and CDK7-HA protein levels.

that this interaction mediates the association between Tat and CAK or TFIIH. Furthermore, Tat stimulated the ability of recombinant CAK, as well as immunoprecipitated CAK/TFIIH complexes to phosphorylate the free CTD and purified Pol II. Finally, whereas basal transcription from the HIV LTR was independent of CDK7, the phosphorylation of the CTD by CDK7 was absolutely essential for Tat transactivation in vitro and in vivo. Together, our results reveal a cellular target of the activation domain of Tat, suggest that the interaction between Tat and its cellular counterpart is critical for the function of Tat, and suggest a model by which Tat increases the processivity of Pol II.

Tat was reported previously to bind to the p62 subunit of TFIIH (Blau et al. 1996; Parada and Roeder 1996). However in our hands, Tat mutants used in this study (C30G, K41A) bound to p62 as well as the wi ld-type Tat (data not shown). Instead, we found a strong and specific interaction between Tat and CDK7. This observation was supported by the finding that $T$ at bound to the recombinant
CAK in vitro with high affinity and specificity. Despite this result, it is possible that additional contacts between Tat and other subunits of TFIIH stabilize further the binding of Tat to TFIIH in vivo. Furthermore, our finding that Tat can bind to TFIIH in vivo is consistent with our previous results demonstrating an interaction between Tat and the Pol II holoenzyme (Cujec et al. 1997).

Our initial experiments confirmed other studies that demonstrated that Tat can increase the ability of TFIIH to phosphorylate the CTD of Pol II (Parada and Roeder 1996; Garcia-M artinez et al. 1997). We extend these findings by demonstrating that $\mathrm{Tat}$ can al so increase the ability of CAK to phosphorylate the CTD and Pol II. AIthough CAK was more efficient at phosphorylating free CTD than Pol II (compare the ratio of substrate phosphorylation with cyclin $\mathrm{H}$ phosphorylation in Figs. 4A and $B$ ), the effect of Tat was evident in both cases. It is possible that when associated with Pol II, the CTD is relatively inaccessible to CAK. Following the interaction of Pol II with TFIIH/TFIIE, SRBs, or TAR and TAR-binding proteins, the CTD of Pol II might become more accessible to phosphorylation. Although Gaynor and colleagues (Garcia-Martinez et al. 1997) reported recently that Tat has only a low affinity for CAK and that it fails to potentiate its kinase activity, these experiments were done using crude fractions from gel filtration columns and the authors themselves suggested that inhibitors in their fractions could mask potential interactions between Tat and CAK.

The CTD of Pol II has an important role in Pol II transcription (Dahmus 1995), in premRNA processing (Yuryev et al. 1996) and polyadenylation (M cCracken et al. 1997). The phosphorylation of the CTD by TFIIH has an important role in the processivity of Pol II (Maldonado and Reinberg 1995). Evidence supporting this hypothesis comes from the observation that the CTDs of polymerases paused on the Drosophila hsp 70 promoter are relatively unphosphorylated, whereas those of actively elongating polymerases are high phosphorylated (O'Brien et al. 1994), and the fact that the inhibition of TFIIH abolishes transcriptional elongation ( $Y$ ankulov et al. 1995; A khtar et al. 1996). Therefore, it is remarkable that our results demonstrating that Tat potentiates the kinase activity of CAK illuminates further the pivotal role of TFIIH in phosphorylating the CTD and ensuring the processivity of Pol II. The mechanism by which phosphorylation of the CTD al lows for increased processivity of Pol II is unknown. However, onemight envision that the phosphorylation of the CTD results in conformational changes in Pol II, which in turn facilitate the escape of the DNA-bound polymerase from the assembled pre-initiation complex, increase the activity of its catalytic subunit, and allow for the binding of new transcription elongation factors.

Previous attempts to demonstrate that the kinase activity of TFIIH is required for Tat transactivation have centered on the use of kinase inhibitors ( $\mathrm{H} 8)$, ATP analogs (DRB), or immunodepletion experiments (Herrmann and Rice 1995; Parada and Roeder 1996). However, these 
approaches were limited by the absence of specific inhibitors to $C D K 7$, and the possibility that the immunodepl etion of TFIIH removed additional proteins or activities ( $3^{\prime} \rightarrow 5^{\prime}$ hel icase of ERCC 3 ) required for the function of Tat. Although pseudosubstrates have been used previously to inhibit kinases such as protein kinase $C$ (Poteet-Smith et al. 1997), we bel ieve ours is the first report of a peptide being used to inhibit the enzymatic activity of a GTF. The use of a mutant CDK2 peptide to inhibit specifically the kinase activity of CDK7 was val idated by the foll owing: (1) the inhibition of the activity of CAK by $m C 2 p$ in in vitro kinase assays; (2) the inhibition of transcription from the CDK7-dependent DHFR promoter; (3) the observation that $\mathrm{mC} 2 \mathrm{p}$ did not affect the transcription from the CDK7-independent AdML promoter; and (4) the observation that $\mathrm{mC} 2 \mathrm{p}$ had no effect on the kinase activity of either CDK8/cyclin C or cyclinA $\Delta 171 /$ CDK2HA. Consequently, we used this peptide to demonstrate that phosphorylation of the CTD by CDK7 is required for the function of Tat in vitro and in vivo. Overexpression of the wild-type and kinase-deficient CDK7 proteins in COS cells confirmed that CDK7 is essential for the production of long transcripts from the HIV LTR. Together these results extend our previous observations demonstrating that the CTD is required for Tat transactivation (Okamoto et al. 1996), and firmly establish that the HIV LTR is an enhancer-dependent promoter.

Based on these results we propose a model for how the function of Tat increases the processivity of Pol II (Fig. 9). Tat enters into the transcription complex by virtue of its association with the Pol II holoenzyme before docking of the complex onto the DNA template. Pol II then copies promoter proximal sequences and TAR is synthesized.

Following its interaction with TAR, Tat is reposi- tioned and/or modified such that it increases the ability of CDK7 to phosphorylate the CTD. Tat might function in a catalytic manner by modifying TFIIH, it may reposition TFIIH in closer proximity of the CTD, or it might increase the length of time that TFIIH remains in contact with the CTD. In this regard it is intriguing that TFIIH remains associated with Pol II for only a relative short period of time foll owing promoter clearance by Pol II (Zawel et al. 1995) and that core Pol II has been reported to interact with both Tat (Mavankal et al. 1996) and TAR (Wu-Baer et al. 1995). Although our data is entirely consistent with the one-step recruitment of Tat to the transcription complex via its interaction with the Pol II holoenzyme, it does not preclude the possibility that additional Tat is also recruited by nascent TAR (Keen et al. 1996). In this manner, other CTD kinases that are not part of the Pol II holoenzyme might be brought into the complex (Herrmann and Rice 1995; Yang et al. 1996). Synergistic effects of multiple kinases might ensure efficient phosphorylation of the Pol II CTD and optimal transcription elongation. The CTD of Pol II remains unphosphorylated despite the fact that TFIIH is present in the Pol II holoenzyme (Ossipow et al. 1995; Chao et al. 1996; Maldonado et al. 1996). Presumably conformational changes in TFIIH, Pol II, and perhaps other transcription factors are required before the kinase activity of TFIIH can be activated (Laybourn and Dahmus 1990; Peterson et al. 1992). The inability of TFIIH to phosphorylate the CTD before docking of the polymerase onto the DN A template would not be affected by the presence of Tat. The mechanism by which Tat increases the processivity of Pol II establi shes important principles of transcriptional el ongation, and suggests a mechanism by which pause sites in other promoters (c-myc) might be circumvented (Wright et al. 1994). Future work on template commitment, the ability of TAR decoys to de- assembly

initiation

promoter clearance

elongation

Tat-TAR interactions

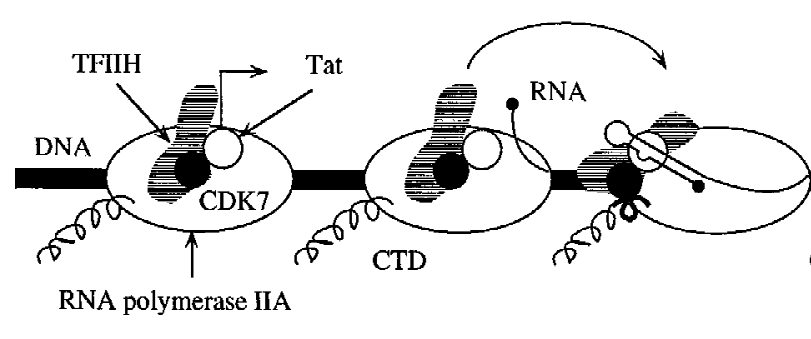

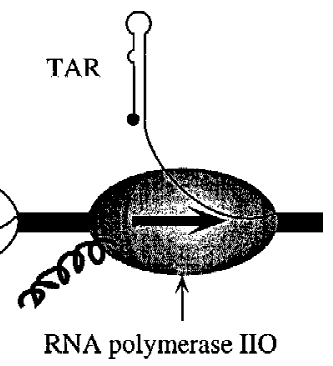

CTD phosphorylation

Figure 9. A model of the mechanism by which Tat increases the processivity of Pol II. As depicted above, transcription from the HIV LTR can be divided into four stages: (1) assembly of the transcription complex onto the DNA template; (2) initiation of transcription; (3) promoter clearance; and (4) el ongation of Pol II al ong the DN A template. In this schematic, the DNA template is depicted by a thick black line, the unphosphorylated form of the core Pol II (IIA) by an open oval with its unphosphorylated CTD as a thin curved line, and the nine subunits TFIIH as striped forms with the CDK7 as a solid circle. Tat is designated as an open circle and the transcription initiation site with an arrow. During assembly of the initiation complex, Tat, TFIIH and other components of the Pol II holoenzyme (omitted for the sake of simplicity) associate with the core Pol II onto the DNA template. Transcription initiates with the hydrolysis of ATP between the $\beta$ and $\gamma$ phosphates and the synthesis of the first phosphodiester bond. N ascent RN A (line with a large dot at its 5' terminus) is synthesized following the promoter clearance. The CTD might be partially phosphorylated at this point and is depicted by a curved line with a partially thickened section. Following synthesis of TAR, Tat binds to the bulge region and is repositioned or modified such that it can increase the ability of TFIIH to phosphorylate the CTD. The highly phosphorylated form of Pol II (IIO), depicted as a shaded oval with its CTD as a thick curved line, is therefore rendered highly processive and can now efficiently transcribe the entire viral genome. 
plete Tat at different stages of transcription, and the mapping of surfaces on CDK7 that interact with Tat will reveal further mechanistic details by which interactions between Tat and TAR stimulate the ability of TFIIH to phosphorylate the CTD of Pol II.

\section{Material and methods}

\section{Immunoprecipitations}

The constructs pCMV-TATHA(Tat) and PCMV-TAT(C30G)HA containing wild-type or mutant Tat (C 30G) fused to the influenza virus HA epitope tag $\left(3^{\prime}\right)$ were described previously (Cujec et al. 1997). A second HA-tagged mutant of Tat (K41A) was constructed by PCR-mediated mutagenesis. Briefly, PCR primers K41A (CATTGCTACGCGTGTTTCACAAGAgCCGGCTTAGGC, lowercase letters denote mutation) and TAT3 (CAGTCTGAGTAGTTCGAAGAGTAG) were used to amplify a 112-bp fragment of Tat that was then cloned into the AflIII and HindIII sites of PCMV-TATHA. Both mutations (C30G, K41A) are in the activation domain of $T$ at and render $T$ at inactive without affecting its RN A-binding ability or protein expression levels (Kuppuswamy et al. 1989; Fig. 1). The Tat constructs (5 $\mu \mathrm{g})$ were transfected into COS-7 cells by liptofectin $(10 \mu \mathrm{l})$ according to the manufacturer's recommendations (GIBCO BRL, Gaithersburg, MD). A pproximately $36 \mathrm{hr}$ after transfection the cells were lysed [50 mM HEPES-KOH at $\mathrm{pH} 7.8,0.5 \mathrm{M} \mathrm{NaCl} 1 \%$ Triton X-100, $10 \mathrm{~mm}$ EDTA, $5 \mathrm{~mm}$ dithiothreitol (DTT), $0.1 \mathrm{~mm}$ phenylmethylsulfonyl fluoride (PMSF), $20 \mu \mathrm{g} / \mathrm{ml}$ of aprotinin $10 \mu \mathrm{g} / \mathrm{ml}$ of leupeptin], and the supernatants immunoprecipitated with the indicated antibodies. Immunoprecipitates bound to protein-A-Sepharose beads were washed three times in CAKbinding buffer (lysis buffer $+10 \%$ glycerol). Washed beads were subjected to gradient $(5 \%-15 \%)$ SDS-PAGE, transferred to Immobilon-N C membranes (Millipore, Bedford, MA) and reacted with the indicated antibodies. The proteins were visualized by enhanced chemiluminescence detection (Amersham, Arlington Heights, IL). The anti-HA antibody was purchased from Boehringer Mannheim (Indianapolis, IN ), the CDK7 antibody from Santa Cruz Biotechnology (Santa Cruz, CA), and the cyclin H antibody from U pstate Biotechnol ogy (Lake Placid, NY) and the Pol II antibody ( $\alpha$ RPB 1 ) from Promega (Madison, WI). The CIITA antibody was from our laboratory (Steimle et al. 1993).

\section{Purification of recombinant CAK trimer}

Recombinant baculoviruses encoding human CDK7 (Fisher and Morgan 1994), M AT1 (Fisher et al. 1995), and an amino-terminally 6-Histidine-tagged version of cyclin $\mathrm{H}$ (Kim et al. 1996) were constructed as described. Sf9 insect cells $\left(4 \times 10^{9}\right)$ were coinfected with all three baculoviruses (multiplicity of infection for each virus: $5 \mathrm{PFU} /$ cell), incubated 2 days at $28^{\circ} \mathrm{C}$, and harvested by centrifugation. Cells were resuspended in $120 \mathrm{ml}$ of buffer A (20 mm Na phosphate, $25 \mathrm{~mm} \mathrm{NaCl}, 1 \mathrm{~mm}$ PM SF, 1 $\mu \mathrm{g} / \mathrm{ml}$ of leupeptin, $2 \mu \mathrm{g} / \mathrm{ml}$ of aprotinin, $1 \mathrm{~mm}$ DTT at pH 7.4). $\mathrm{NaCl}$ concentration was raised to $300 \mathrm{~mm}$ and the lysate was clarified by centrifugation and loaded over tandem 5-ml Pharmacia HiTrap chelating columns loaded with $\mathrm{CoCl}_{2}$ and preequilibrated with buffer $\mathrm{B}(300 \mathrm{~mm} \mathrm{~N} \mathrm{aCl}, 20 \mathrm{~mm} \mathrm{~N}$ a phosphate, $10 \%$ glycerol at $\mathrm{pH}$ 7.2). The column was washed with buffer $\mathrm{B}+1 \mathrm{~mm}$ DTT and eluted with a linear gradient of $0-200 \mathrm{~mm}$ imidazole in buffer $B+1 \mathrm{~mm}$ DTT. Fractions containing the CAK trimer were pooled, diluted fourfold in buffer $C(20 \mathrm{~mm}$ HEPES- $\mathrm{NaOH}, 1 \mathrm{~mm}$ EDTA, 10\% glycerol, $1 \mathrm{~mm}$ DTT at $\mathrm{pH}$ 7.4), and loaded on a 5-ml Pharmacia HiTrap Q column pre- equilibrated with buffer $C$. The column was washed with buffer $\mathrm{C}$ and eluted with a linear gradient of $25-1000 \mathrm{mM} \mathrm{NaCl}$ in buffer $\mathrm{C}$. Fractions containing the CAK trimer were pooled and subjected to gel filtration on a 125-ml Pharmacia Superdex 200 column pre-equilibrated in buffer $\mathrm{C}+150 \mathrm{~mm} \mathrm{NaCl}$. Peak fractions were concentrated by ion exchange on a 1-ml Pharmacia HiTrap Q column. The pure CAK trimer $(2 \mathrm{mg} / \mathrm{ml}$; $>99 \%$ homogeneous) was stored at $-80^{\circ} \mathrm{C}$.

\section{In vitro binding assays}

For the CAK-binding assays, wild-type Tat (ST at) or mutant T at ( $T$ atK 41A) proteins containing at their $3^{\prime}$ ends both a phosphorylation site for the CAMP-dependent heart muscle kinase and a streptavidin binding peptide, were expressed in bacteria and bound to streptavidin-agarose beads as described previously (Cujec et al. 1997). Equilibrated Tat streptavidin-agarose beads were incubated with $250 \mu \mathrm{g}$ of nuclear extract or $50 \mathrm{ng}$ of purified CAK as described above. Pelleted beads were washed four times in CAK-binding buffer (see above), and processed as described in the immunoprecipitation protocol. For the CDK7binding assays, Tat was eluted from the streptavidin-agarose beads with $0.8 \mathrm{M} \mathrm{N} \mathrm{aCl}$ and $2 \mathrm{~mm}$ bi otin and dialyzed into buffer D (25 mM HEPES- $\mathrm{KOH}$ at pH 7.6, $0.1 \mathrm{~m} \mathrm{KCl,} 20 \%$ glycerol, 10 mM DTT, $0.1 \mathrm{~mm}$ EDTA). Approximately $50 \mathrm{ng}$ of eluted Tat was label ed using 10 units of catalytic subunit of CAM P-dependent heart muscle kinase (Sigma P-2645) and $20 \mu \mathrm{Ci}$ of $[\gamma$ ${ }^{32} \mathrm{PJATP}$. Kinase reactions were performed in $50 \mu \mathrm{l}$ of $0.1 \mathrm{M}$ Tris at pH 7.5, $5 \mathrm{~mm}$ DTT, $0.5 \mathrm{M} \mathrm{NaCl}, 60 \mathrm{~mm} \mathrm{M} \mathrm{gCl}$. CDK7, cyclin $\mathrm{H}$, and MAT 1 proteins were labeled with $L-\left[{ }^{35}\right.$ S]methionine $(>1000 \mathrm{Ci} / \mathrm{mmole}$; Amersham) and the Promega TNT protein expression system. CAK complexes were formed in association buffer (20 mM HEPES-KOH at pH 7.6, $50 \mathrm{~mm} \mathrm{KCl}, 10 \mathrm{~mm}$ DTT, $5 \mathrm{~mm}$ EDTA, and $10 \%$ glycerol) for $1 \mathrm{hr}$ at $4^{\circ} \mathrm{C}$ and then immunoprecipitated with $\alpha$ CDK7 antibodies attached to protein-ASepharose beads. After binding, the beads were washed three times in the association buffer and then two times in CAKbinding buffer (see above). Label ed Tat $(0.5 \mathrm{ng})$ was added to the CDK7 complexes and incubated for $1 \mathrm{hr}$ at $25^{\circ} \mathrm{C}$. Beads were washed again with binding buffer and then with PBS before loading onto SDS-PAGE (5\%-20\% gradient). After drying, the gels were visualized by autoradiography.

\section{Kinase reactions}

GST-CTD fusion proteins were expressed in Escherichia coli using pGCTD (a generous gift of W. Dynan) as described (Peterson et al. 1992). Fusion proteins were eluted from glutathioneSepharose beads with $15 \mathrm{~mm}$ glutathione and purified by gel filtration on a S-300 column (Pharmacia, Piscataway NJ). Approximately $25 \mathrm{ng}$ of the eluted GST-CTD fusion was used in each kinase reaction. Purified preparations of Pol II (a generous gift of C. Kane) were obtained as described (Hodo and Blatti 1977; Kerppola and Kane 1990) except that a Mono S column was used instead of a DEAE-5PW column in the final step of the purification. CAK/TFIIH complexes were immunoprecipitated from HeLa-cells that stably expressed HA-tagged wild-type CDK7 or a kinase-deficient mutant (D155A) under the control of a tetracycline-repressible promoter (Jin et al. 1996). Cells were lysed (50 mM HEPES- $\mathrm{KOH}$ at $\mathrm{pH} 7.6,150 \mathrm{~mm} \mathrm{~N} \mathrm{aCl}, 5 \mathrm{~mm}$ EDTA, $0.1 \%$ Triton $X-100,5 \mathrm{~mm}$ DTT, $0.2 \mathrm{~mm}$ PMSF, $1 \mathrm{~mm}$ $\mathrm{NaF}, 0.1 \mathrm{~mm} \mathrm{NaVO}{ }_{4} 10 \mu \mathrm{g} / \mathrm{ml}$ of aprotinin, $1 \mu \mathrm{g} / \mathrm{ml}$ leupeptin) and immunoprecipitations done as described above. Typically, wild-type CAK/TFIIH complexes were immunoprecipitated from four 150-mm culture dishes after four days of growth in the absence of tetracycline $(10 \mathrm{mg} / \mathrm{ml})$. Immunoprecipitated 
beads were washed three times with lysis buffer and then two times with CTD-kinase buffer $(20 \mathrm{~mm}$ Tris at pH 7.6, $50 \mathrm{~mm}$ $\mathrm{KCl}, 5 \mathrm{~mm} \mathrm{M} \mathrm{gCl} 2,2.5 \mathrm{~mm} \mathrm{M} \mathrm{nCl}_{2}, 10 \mathrm{~mm}$ DTT). Reactions were supplemented with $10 \mu \mathrm{Ci}$ of $\left[\gamma^{32} \mathrm{P}\right] \mathrm{ATP}$ and $50 \mu \mathrm{M}$ of unlabel ed ATP in a final reaction volume of $50 \mu \mathrm{l}$. Reactions were incubated for $1 \mathrm{hr}$ at $30^{\circ} \mathrm{C}$. In some experiments, recombinant CAK (50 ng) or casein kinase II (25 ng) (U pstate Biotechnology) was used as the source of kinase activity. Peptide concentrations were determined by the ESL Protein Assay (Boehringer Mannheim) system. The sequences of $m C 2 p$ and $r C 2 p$ are ARAFGVPVRTYaHEVVTLWYRA (lowercase letter denotes residue mutated from threonine) and HARTVGVWYRAEYARFVTPaVV, respectively. Histone $\mathrm{H} 1$ kinase assays were done as reported previously (Fisher and Morgan 1994).

\section{In vitro transcription reactions}

Run-off transcription reactions from the wild-type HIV LTR and $\mathrm{AdML}$ promoters linearized with $\mathrm{Ncol}$ and $\mathrm{HindlII}$, respectively, were carried out as described (Okamoto et al. 1996; Cujec et al . 1997). Transcription reactions containing the DHFR promoter (500 ng) fused to a G-less cassette (linearized at N col) were supplemented with $3 \mathrm{~mm}\left(\mathrm{~N} \mathrm{H}_{4}\right)_{2} \mathrm{SO}_{4}, 2 \%$ PEG 8000, 50 units of T 1 RN ase (Boehringer $M$ annheim), 500 units of RN ase inhibitor (Boehringer $M$ annheim) and contained $5 \mu \mathrm{m}$ instead of $40 \mu \mathrm{m}$ of unlabeled UTP. Phosphocreatine, poly[d(I-C)], and poly[r(I-C)] were omitted from the reactions.

\section{RNase protection assays}

For the peptide inhibition studies $1 \times 10^{7} \mathrm{COS}-7$ cells were el ectroporated $(500 \mu \mathrm{l})(\mathrm{Bio}-\mathrm{Rad}, \mathrm{Hercules}, \mathrm{CA})$ at $210 \mathrm{~V}, 960 \mathrm{mF}$, using $2 \mu \mathrm{g}$ of reporter DNA (pHIV $\triangle$ KBCAT) containing HIV LTR sequences lacking NF-kB-binding sites, $2 \mu \mathrm{g}$ of effector DNA (pSVTAT or pSVTATZX) and varying concentrations of $\mathrm{mC} 2 \mathrm{p}$ or $\mathrm{rC} 2 \mathrm{p}(1 \mu \mathrm{g} / \mu \mathrm{l}$ of solution). For the CDK7 overexpression studies, COS-7 cells were transfected with lipofectin using $2 \mu \mathrm{g}$ of reporter DN A (HIVSCAT and 4XSp1), and $2 \mu \mathrm{g}$ of effector DNA (pSVTAT or pSVTATZX) as described above. Vector al one or plasmids encoding HA-tagged wild-type CDK7 (SR $\alpha$-CDK7$\mathrm{HA}$ ) or mutant HA-tagged CDK7 [SR $\alpha-C D K 7(D 155 A)-H A]$ were cotransfected as indicated. Cells were incubated in the Opti-MEM medium for $5 \mathrm{hr}$ and harvested $48 \mathrm{hr}$ after transfection. Twenty micrograms of RNA was used for the RN ase protection assays. To make the rabbit $\beta$-globin or the HIV LTR CAT probe, Sp6 $\beta$ TS or pGEMI/WT vectors were linearized with EcoRI and transcribed with Sp6 or T 7 polymerases, respectively, to produce $\left[\alpha-{ }^{32} \mathrm{P}\right] \mathrm{UTP}$-labeled RNA probes. Assays were performed as described (Okamoto et al. 1996), the protected fragments were separated on $11 \%$ polyacrylamide/ urea sequencing gels and processed as outlined above.

\section{Acknowledgments}

We thank Michael Armanini for excellent secretarial assistance and members of our laboratories for comments on the manuscript. We thank Sasha Akoulitchev, Ron Drapkin, and Danny Reinbergfor antibodies, TFIIH preparations, plasmids, and helpful suggestions. We are grateful to Ken Sakurabayashi and W. Dynan for the PGCTD construct, and to Caroline Kane and Rodney Weilbaecher for the purified core Pol II preparations. T.P.C. was funded by a Fellowship from the University-wide Taskforce on AIDS.

The publication costs of this article were defrayed in part by payment of page charges. This article must therefore be hereby marked "advertisement" in accordance with 18 USC section 1734 solely to indicate this fact.

\section{References}

Akhtar, A., G. Faye, and D.L. Bentley. 1996. Distinct activated and non-activated RNA polymerase II complexes in yeast. EMBO J. 15: 4654-4664.

Akoulitchev, S., T.P. Makela, R.A. Weinberg, and D. Reinberg. 1995. Requirement for TFIIH kinase activity in transcription by RNA polymerase II. Nature 377: 557-560.

Alonso, A., D. Derse, and B.M. Peterlin. 1992. Human chromosome 12 is required for optimal interactions between $T$ at and TAR of human immunodeficiency virus type 1 in rodent cells. J. Virol. 66: 4617-4621.

Blau, J., H. Xiao, S. M cCracken, P. O'Hare, J. Greenblatt, and D. Bentley. 1996. Three functional classes of transcriptional activation domains. Mol. Cell. Biol. 16: 2044-2055.

Carroll, R., B.M. Peterlin, and D. Derse. 1992. Inhibition of human immunodeficiency virus type 1 Tat activity by coexpression of heterologous trans-activators. J. Virol. 66: 20002007.

Chao, D.M., E.L. Gadbois, P.J. Murray, S.F. Anderson, M.S. Sonu, J.D. Parvin, and R.A. Young. 1996. A mammalian SRB protein associated with an RNA polymerase II holoenzyme. Nature 380: 82-85.

Chiang, C.-M. and R.G. Roeder. 1995. Cloning of an intrinsic human TFIID subunit that interacts with multiple transcriptional activators. Nature 267: 531-536.

Chun, R.F., and K.T. Jeang. 1996. Requirements for RN A polymerase II carboxyl-terminal domain for activated transcription of human retroviruses human $\mathrm{T}$-cell lymphotropic virus I and HIV-1. J. Biol. Chem. 271: 27888-27894.

Cismowski, M.J., G.M. Laff, M.J. Solomon, and S.I. Reed. 1995. KIN 28 encodes a C-terminal domain kinase that controls mRN A transcription in Saccharomyces cerevisiae but lacks cyclin-dependent kinase-activating kinase (CAK) activity. Mol. Cell. Biol. 15: 2983-2992.

Cujec, T.P., H. Cho, E. Maldonado, J. Meyer, D. Reinberg, and B.M. Peterlin. 1997. The human immunodeficiency virus transactivator Tat interacts with the RN A polymerase II hoIoenzyme. Mol. Cell. Biol. 17: 1817-1823.

Cullen, B.R. 1993. Does HIV-1 Tat induce a change in viral initiation rights? Cell 73: 417-420.

Dahmus, M.E. 1994. The role of multisite phosphorylation in the regulation of RNA polymerase II activity. Prog. Nucleic Acid Res. Mol. Biol. 48: 143-179.

- - - 1995. Phosphorylation of the C-terminal domain of RN A polymerase II. Biochim. Biophys. Acta. 1261: 171-182.

- - - 1996. Phosphorylation of mammalian RNA polymerase II. Methods Enzymol. 273: 185-193.

Desai, K., P.M. Loewenstein, and M. Green. 1991. Isolation of a cellular protein that binds to the human immunodeficiency virus $T$ at protein and can potentiate transactivation of the viral promoter. Proc. Natl. Acad. Sci. 88: 8875-8879.

Drapkin, R. and D. Reinberg. 1994. The multifunctional TFIIH complex and transcriptional control. Trends Biochem. Sci. 19: 504-508.

Drapkin, R., G. LeRoy, H. Cho, S. Akoulitchev, and D. Reinberg. 1996. Human cyclin-dependent kinase-activating kinase exists in three distinct complexes. Proc. Natl. Acad. Sci. 93: 6488-6493.

Feaver, W.J., O. Gileadi, Y. Li, and R.D. Kornberg. 1991. CTD kinase associated with yeast RNA polymerase II initiation factor b. Cell 67: 1223-1230. 
Feaver, W.J., J.Q. Svejstrup, N.L. Henry, and R.D. Kornberg. 1994. Relationship of CDK-activating kinase and RN A polymerase II CTD kinase TFIIH/TFIIK. Cell 79: 1103-1109.

Fisher, R.P. and D.O. Morgan. 1994. A novel cyclin associates with MO15/CDK7 to form the CDK-activating kinase. Cell 78: 713-724.

Fisher, R.P., P. Jin, H.M. Chamberlin, and D.O. Morgan. 1995. Alternative mechanisms of CAK assembly require an assembly factor or an activating kinase. Cell 83: 47-57.

Garcia-M artinez, L.F., G. M avankal, J.M. N eveu, W.S. Lane, D. Ivanov, and R. B. Gaynor. 1997. Purification of a Tat-associated kinase reveals a TFIIH complex that modulates HIV-1 transcription. EMBO J. 16: 2836-2850.

Gerber, H.P., M. Hagmann, K. Seipel, O. Georgiev, M.A. West, Y. Litingtung, W. Schaffner, and J.L. Corden. 1995. RNA polymerase II C-terminal domain required for enhancerdriven transcription. Nature 374: 660-662.

Hart, C.E., C.Y. Ou, J.C. Galphin, J. Moore, L.T. Bacheler, J.J. Wasmuth, S. Petteway Jr., and G. Schochetman. 1989. Human chromosome 12 is required for el evated HIV-1 expression in human-hamster hybrid cells. Science 246: 488-491.

Herrmann, C.H., and A.P. Rice. 1995. Lentivirus Tat proteins specifically associate with a cellular protein kinase, TAK, that hyperphosphorylates the carboxyl-terminal domain of the large subunit of RNA polymerase II: Candidate for a Tat cofactor. J. Virol. 69: 1612-1620.

Hodo III, H.G. and S.P. Blatti. 1977. Purification using polyethylenimine precipitation and low molecular weight subunit analyses of calf thymus and wheat germ DNA-dependent RN A polymerase II. Biochemistry 16: 2334-2343.

Hoeijmakers, J.H.J., J.-M . Egly, and W. Vermeulen. 1996. TFIIH: A key component in multiple DNA transactions. Curr. Opin. Genet. Dev. 6: 26-33.

Jeang, K.T., R. Chun, N.H. Lin, A. Gatignol, C.G. Glabe, and H. Fan. 1993. In vitro and in vivo binding of human immunodeficiency virus type 1 Tat protein and Spl transcription factor. J. Virol. 67: 6224-6233.

Jin, P., Y. Gu, and D.O. M organ. 1996. Role of inhibitory CDC2 phosphorylation in radiation-induced G2 arrest in human cells. J. Cell Biol. 134: 963-970.

Jones, K.A. and B.M. Peterlin. 1994. Control of RNA initiation and el ongation at the HIV-1 promoter. Annu. Rev. Biochem. 63: 717-743.

Kao, S. Y., A.F. Calman, P.A. Luciw, and B.M. Peterlin. 1987 Anti-termination of transcription within the long terminal repeat of HIV-1 by Tat gene product. Nature 330: 489-493.

Kashanchi, F., G. Piras, M.F. Radonovich, J.F. Duvall, A. Fattaey, C.M. Chiang, R.G. Roeder, and J.N . Brady. 1994. Direct interaction of human TFIID with the HIV-1 transactivator Tat. Nature 367: 295-299.

Kato, H., H. Sumimoto, P. Pognonec, C.H. Chen, C.A. Rosen, and R.G. Roeder. 1992. HIV-1 Tat acts as a processivity factor in vitro in conjunction with cellular el ongation factors. Genes \& Dev. 6: 655-666.

Keen, N.J., M.J. Gait, and J. Karn. 1996. Human immunodeficiency virus type-1 Tat is an integral component of the activated transcription-el ongation complex. Proc. Natl. Acad. Sci. 93: 2505-2510.

Kerppola, T.K. and C.M. Kane. 1990. Analysis of the signals for transcription termination by purified RNA polymerase II. Biochemistry 29: 269-278.

Kim, K.-K., H.M. Chamberlin, D.O. Morgan, and S.-H. Kim. 1996. Three-dimensional structure of human cyclin $\mathrm{H}$, a positive regulator of the CDK-activating kinase. Nature Struct. Biol. 3: 849-855.

Kim, Y.J., S. Bjorklund, Y. Li, M.H. Sayre, and R.D. Kornberg.
1994. A multiprotein mediator of transcriptional activation and its interaction with the C-terminal repeat domain of RNA polymerase II. Cell 77: 599-608.

Kladis, P., A. Sutton, and M. Solomon. 1996. The CDK-activating kinase (CAK) from budding yeast. Cell 86: 553-564.

Kuppuswamy, M., T. Subramanian, A. Srinivasan, and G. Chinnadurai . 1989. Multiple functional domains of Tat, the transactivator of HIV-1, defined by mutational analysis. Nucleic Acids Res. 17: 3551-3561.

Laspia, M.F., A.P. Rice, and M.B. Mathews. 1989. HIV-1 Tat protein increases transcriptional initiation and stabilizes elongation. Cell 59: 283-292.

Laybourn, P.J., and M.E. Dahmus. 1989. Transcription-dependent structural changes in the $\mathrm{C}$-terminal domain of mammalian RNA polymerase subunit Ila/o. J. Biol. Chem. 264: 6693-6698.

- - . 1990. Phosphorylation of RNA polymerase lla occurs subsequent to interaction with the promoter and before the initiation of transcription. J. Biol. Chem. 265: 13165-13173.

Liao, S.M., J. Zhang, D.A. Jeffery, A.J. Kol eske, C.M. Thompson, D.M. Chao, M. Viljoen, H.J. van Vuuren, and R.A. Young. 1995. A kinase-cyclin pair in the RNA polymerase II holoenzyme. Nature 374: 193-196.

Lu, H., L. Zawel, L. Fischer, J.-M. Egly, and D. Reinberg. 1992. Human general transcription factor IIH phosphorylates the C-terminal domain of RN A polymerase II. Nature 358: 641645.

Lu, X., T.M. Welsh, and B.M. Peterlin. 1993. The human immunodeficiency virus type 1 long terminal repeat specifies two different transcription complexes, only one of which is regulated by Tat. J. Virol. 67: 1752-1760.

Madore, S.J., and B.R. Cullen. 1995. Functional similarities between HIV-1 Tat and DN A sequence-specific transcriptional activators. Virology 206: 1150-1154.

Madore, S.J. and B.R. Cullen. 1993. Genetic analysis of the cofactor requirement for human immunodeficiency virus type 1 Tat function. J. Virol. 67: 3703-3711.

Makela, T.P., J.P. Tassan, E.A. Nigg, S. Frutiger, G.J. Hughes, and R.A. Weinberg. 1994. A cyclin associated with the CDKactivating kinase M O15. Nature 371: 254-257.

Maldonado, E. and D. Reinberg. 1995. N ews on initiation and elongation of transcription by RNA polymerase II. Curr. Opin. Cell Biol. 7: 352-361.

M al donado, E., R. Shiekhattar, M. Shel don, H. Cho, R. Drapkin, J.A. Inostroza, P. Rickert, E. Lees, C.W. Anderson, S. Linn, and D. Reinberg. 1996. A human RNA polymerase II complex associated with SRB and DNA-repair proteins. Nature 381: 86-89.

Marciniak, R.A. and P.A. Sharp. 1991. HIV-1 Tat protein promotes formation of more processive elongation complexes. EMBO J. 10: 4189-4196.

Mavankal, G., S.H. Ou, H. Oliver, D. Sigman, and R.B. Gaynor. 1996. Human immunodeficiency virus type 1 and 2 proteins specifically interact with RNA polymerase II. Proc. Natl. Acad. Sci. 93: 2089-2094.

McCracken, S., N. Fong, K. Yankulov, S. Ballantyne, G. Pan, J. Greenblatt, S. D. Patterson, M. Wickens, and D.L. Bentley. 1997. The C-terminal domain of RNA polymerase II couples mRNA processing to transcription. Nature 385: 357-361.

Nelbock, P., P.J. Dillon, A. Perkins, and C.A. Rosen. 1990. A CDN A for a protein that interacts with the human immunodeficiency virus Tat transactivator. Science 248: 1650-1653.

O'Brien, T., S. Hardin, A. Greenleaf, and J.T. Lis. 1994. Phosphorylation of RNA polymerase II C-terminal domain and transcriptional el ongation. Nature 370: 75-77.

Okamoto, H., C.T. Sheline, J. Corden, K.A. Jones, and B.M. Pe- 
terlin. 1996. Trans-activation by human immunodeficiency virus Tat protein requires the C-terminal domain of RNA polymerase II. Proc. Natl. Acad.Sci. 93: 11575-11579.

Ossipow, V., J.P. Tassan, E.A. N igg, and U. Schibler. 1995. A mammalian RNA polymerase II holoenzyme containing all components required for promoter-specific transcription initiation. Cell 83: 137-146.

Parada, C.A. and R.G. Roeder. 1996. Enhanced processivity of RN A polymerase II triggered by Tat-induced phosphorylation of its carboxy-terminal domain. Nature 384: 375-378.

Peterson, S.R., A. Dvir, C.W. Anderson, and W.S. Dynan. 1992. DNA binding provides a signal for phosphorylation of the RNA polymerase II heptapeptide repeats. Genes \& Dev. 6: 426-438.

Poteet-Smith, C.E., J.B. Shabb, S.H. Francis, and J.D. Corbin. 1997. Identification of critical determinants for autoinhibition in the pseudosubstrate region of type I al pha CAMPdependent protein kinase. J. Biol. Chem. 272: 379-388.

Ratnasabapathy, R., M. Sheldon, L. Johal, and N. Hernandez. 1990. The HIV-1 long terminal repeat contains an unusual element that induces the synthesis of short RN As from various mRNA and snRNA promoters. Genes \& Dev. 4: 20612074.

Reardon, J.T., H. Ge, E. Gibbs, A. Sancar, J. Hurwitz, and Z.Q. Pan. 1996. Isolation and characterization of two human transcription factor IIH (TFIIH)-related complexes: ERCC2/CAK and TFIIH. Proc. Natl. Acad. Sci. 93: 6482-6487.

Rossignol, M., I. Kolb-Cheynel, and J.-M. Egly. 1997. Substrate specificity of the cdk-activating kinase (CAK) is al tered upon association with TFIIH. EMBO J. 16: 1628-1637.

Roy, R., J.P. Adamczewski, T. Seroz, W. Vermeulen, J.P. Tassan, L. Schaeffer, E.A. Nigg, J.H. Hoeijmakers, and J.M. Egly. 1994. The MO15 cell cycle kinase is associated with the TFIIH transcription-DN A repair factor. Cell 79: 1093-1101.

Selby, M.J., E.S. Bain, P.A. Luciw, and B.M. Peterlin. 1989. Structure, sequence, and position of the stem-loop in TAR determine transcriptional elongation by Tat through the HIV-1 long terminal repeat. Genes \& Dev. 3: 547-558.

Serizawa, H., T.P. Makela, J.W. Conaway, R.C. Conaway, R.A. Weinberg, and R.A. Young. 1995. Association of Cdk-activating kinase subunits with transcription factor TFIIH. Nature 374: 280-282.

Shel don, M., R. Ratnasabapathy, and N. Hernandez. 1993. Characterization of the inducer of short transcripts, a human immunodeficiency virus type 1 transcriptional element that activates the synthesis of short RNAs. Mol. Cell. Biol. 13: 1251-1263.

Shiekhattar, R., F. Mermelstein, R.P. Fisher, R. Drapkin, B. Dynlacht, H.C. Wessling, D.O. Morgan, and D. Reinberg. 1995. Cdk-activating kinase complex is a component of human transcription factor TFIIH. Nature 374: 283-287.

Steimle, V., L.A. Otten, M. Zufferey, and B. Mach. 1993. Complementation cloning of an $\mathrm{MHC}$ class II transactivator mutated in hereditary M HC class II deficiency (or bare lymphocyte syndrome). Cell 75: 135-146.

Thompson, N.E., T.H. Steinberg, D.B. Aronson, and R.R. Burgess. 1989. Inhibition of in vivo and in vitro transcription by monoclonal antibodies prepared against wheat germ RNA polymerase II that react with the heptapeptide repeat of eukaryotic RNA polymerase II. J. Biol. Chem. 264: 1151111520.

Thuret, J.-Y., J.-G. Valay, G. Faye, and C. Mann. 1996. Civ 1(CAK in vivo), a novel cdk-activating kinase. Cell 86: 565576.

Tong-Starksen, S.E., P.A. Luciw, and B.M. Peterlin. 1987. Human immunodeficiency virus long terminal repeat responds to T cell activation signals. Proc. Natl. Acad. Sci. 84: 68456849.

Veschambre, P., P. Simard, and P. Jalinot. 1995. Evidence for functional interaction between the HIV-1 Tat transactivator and the TATA box binding protein in vivo. J. Mol. Biol. 250: 169-180.

Wilson, C.J., D.M. Chao, A.N. Imbalzano, G.R. Schnitzler, R.E. Kingston, and R.A. Young. 1996. RNA polymerase II holoenzyme contains SWI/SN F regulators involved in chromatin remodeling. Cell 84: 235-244.

Wright, S., X. Lu, and B.M. Peterlin. 1994. Human immunodeficiency virus type 1 Tat directs transcription through attenuation sites within the mouse c-myc gene. J. Mol. Biol. 243: 568-573.

Wu-Baer, F., D. Sigman, and R.B. Gaynor. 1995. Specific binding of RN A polymerasell to the human immunodeficiency virus trans-activating region RNA is regulated by cellular cofactors and Tat. Proc. Natl. Acad. Sci. 92: 7153-7157.

Yang, X., C.H. Herrmann, and A.P. Rice. 1996. The human immunodeficiency virus Tat proteins specifically associate with TAK in vivo and require the carboxyl-terminal domain of RNA polymerase II for function. J. Virol. 70: 4576-4584.

Yankulov, K.Y. and D.L. Bentley. 1997. Regulation of CDK7 substrate specificity by MATI and TFIIH. EMBO J. 16: 1638-1646.

Yankulov, K., K. Yamashita, R. Roy, J.-M. Egly, and D. Bentley. 1995. The transcriptional el ongation inhibitor 5,6-dichlor-1$\beta$-D-ribofuranosyl benzimidazole inhibits transcription factor IIH-associated protein kinase. J. Biol. Chem. 270: 2392223925.

Yankulov, K.Y., M. Pandes, S. McCraken, D. Bouchard, and D. Bentley. 1996. TFIIH functions in regulating transcriptional elongation by RNA polymerase II in Xenopus oocytes. Mol. Cell. Biol. 16: 3291-3299.

Yuryev, A., M. Patturajan, Y. Litingtung, R.V. Joshi, C. Gentile, M. Gebara, and J.L. Corden. 1996. The C-terminal domain of the largest subunit of RNA polymerase II interacts with a novel set of serine/arginine-rich proteins. Proc. Natl. Acad. Sci. 93: 6975-6980.

Zawel, L., K.P. Kumar, and D. Reinberg. 1995. Recycling of the general transcription factors during RN A polymerase II transcription. Genes \& Dev. 9: 1479-1490.

Zhou, Q. and P.A. Sharp. 1996. Tat-SF1: Cofactor for stimulation of transcriptional elongation by HIV-1 Tat. Science 274: 605-610. 


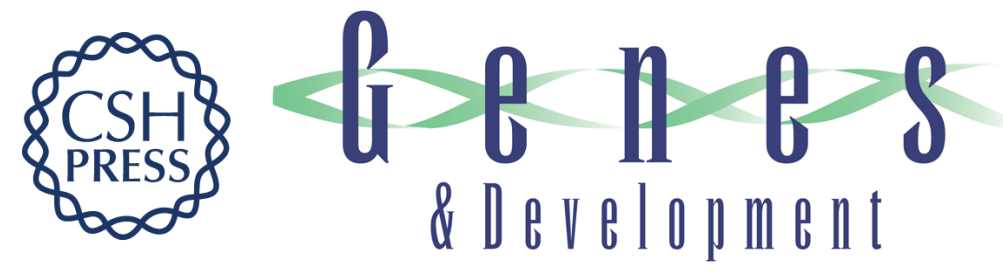

\section{The HIV transactivator TAT binds to the CDK-activating kinase and activates the phosphorylation of the carboxy-terminal domain of RNA polymerase II}

Thomas P. Cujec, Hiroshi Okamoto, Koh Fujinaga, et al.

Genes Dev. 1997, 11:

Access the most recent version at doi:10.1101/gad.11.20.2645

References This article cites 82 articles, 39 of which can be accessed free at:

http://genesdev.cshlp.org/content/11/20/2645.full.html\#ref-list-1

License

Email Alerting Receive free email alerts when new articles cite this article - sign up in the box at the top

Service right corner of the article or click here.

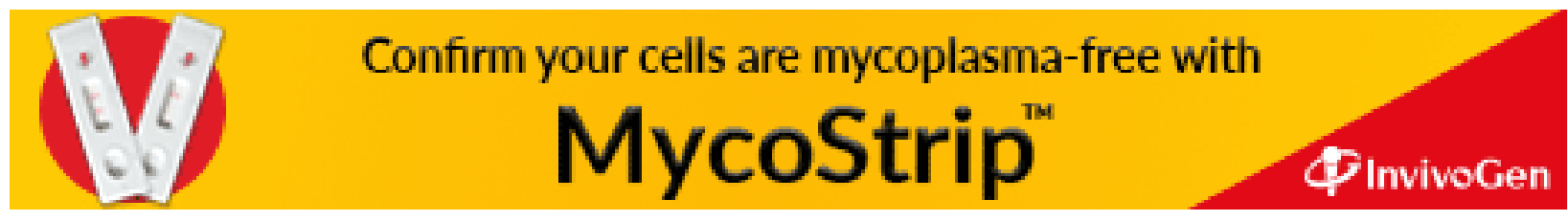

